\title{
Ocorrência de Plantas daninhas no Cultivo de Bromélias ${ }^{1}$
}

\author{
Weed Ocurrence on Bromeliaceae Cultivation
}

\author{
RODRIGUES, I.M.C. ${ }^{2}$, FERREIRA, F.A. ${ }^{3}$, GROSSI, J.A.S. ${ }^{3}$, BARBOSA, J.G. ${ }^{3}$, PAULA, C.C. ${ }^{4}$ e \\ REIS, M.R. ${ }^{5}$
}

\begin{abstract}
RESUMO - A família Bromeliaceae, dentre a grande variedade de plantas tropicais nativas do Brasil, tem merecido destaque devido à sua importância econômica como plantas ornamentais, sendo atualmente muito cultivadas e utilizadas na decoração de interiores e em projetos paisagísticos. Alguns gêneros são endêmicos da Floresta Atlântica e, em função dessa procura, a retirada de seus ambientes naturais constitui ameaça a algumas espécies. A Unidade de Pesquisa e Conservação de Bromeliaceae (UPCB), localizada na Universidade Federal de Viçosa (UFV), MG, tem como finalidade promover a pesquisa em favor da conservação da família Bromeliaceae. Um problema constante na manutenção desse acervo é a infestação por plantas daninhas. Objetivou-se neste trabalho definir as espécies de plantas daninhas críticas no cultivo de bromélias. Foram realizadas visitas semanais, no período de 17 de novembro de 2006 a 17 de janeiro de 2007, para caracterização do comportamento das espécies de plantas daninhas no cultivo de bromélias na UPCB. Após esse período, realizou-se capina manual dos vasos e triagem das espécies daninhas, que foram identificadas e quantificadas. As espécies críticas foram descritas e seus indivíduos férteis depositados no Herbário VIC, do Departamento de Biologia Vegetal, como material testemunha. Realizou-se, também, documentação fotográfica das espécies durante o período de infestação. Foram identificadas duas espécies criticas: brilhantina (Pilea microphylla), com média de seis indivíduos por vaso, e agriãozin ho (Cardamine bonariensis), com média de 13 indivíduos por vaso; sete espécies consideradas potencialmente críticas, com destaque para barba-de-falcão (Crepis japonica); e 12 espécies oportunistas.
\end{abstract}

Palavras-chave: competição, bromeliário, Pilea microphylla, Cardamine bonariensis.

\begin{abstract}
The Bromeliaceae family stands out among the greatvariety of Brazilian native tropical plants because of the economic importance of its ornamental plants, currently widely cultivated and used for indoors decorations and landscape projects. Some genera are endemic to the Atlantic Forest and to meet their great demand, removal from their natural environment has become a threat to some species. The Research and Conservation of Bromeliaceae (UPCB) Unit of the Universidade Federal de Vicosa, in Vicosa, MG promotes research on Bromeliaceae conservation. Weed infestation is a constant problem in the maintenance of this collection. The objective of this work was to define the most critical weeds in bromeliad cultivation. From November 2006 to January 2007, weekly visits were conducted to the collection of bromeliads planted in pots at the UPCB, aiming to characterize the occurrence and behavior of weed species. After this period, the weeds were manually removed from the pots, identified and quantified. The critical weed species were described and their fertile individuals were included in the VIC Herbarium of the Department of Plant Biology, as checks. Photographic documentation of the weeds was also conducted. Two critical species were identified: Pilea microphylla, with around six individuals per pot, and Cardamine
\end{abstract}

Recebido para publicação em 25.4.2007 e na forma revisada em 29.11.2007.

2 Mestranda do Departamento de Fitotecnia da Universidade Federal de Viçosa UF V, 36570-000 Viçosa-MG, <izabellamcr@yahoo.com.br>; ${ }^{3}$ Professor do Departamento de Fitotecnia da UFV; ${ }^{4}$ Professor do Departamento de Biologia Vegetal da UFV; ${ }^{5}$ Doutorando do Departamento de Fitotecnia da UFV. 
bonariensis, with approximately 13 individuals per pot. Seven other species were considered potentially critical, with Crepis japonica being the most important one. Twelve opportunistic species were also identified.

Keywords: competition, bromeliaceae cultivation, Pilea microphylla, Cardamine bonariensis.

\section{INTRODUÇÃO}

A floricultura, como atividade agrícola, envolve o cultivo de plantas ornamentais, desde flores de corte e plantas em vasos, floríferas ou não, até a produção de sementes, bulbos e mudas de árvores de grande porte. Trata-se de um setor muito competitivo, que exige utilização de tecnologia avançada, conhecimento técnico pelo produtor e sistema eficiente de distribuição e comercialização. Atualmente, o campo de floricultura no Brasil está em fase de expansão significativa; até a década de 1950, ele tinha pouca expressão econômica, caracterizando-se como atividade marginal na agricultura (Sebrae, 2003).

O Brasil dispõe de grande diversidade de plantas ornamentais tropicais, com características exóticas e, ainda, pouco exploradas pelo mercado de plantas e flores ornamentais (Borges et al., 2001). Como exemplo, destacase a família Bromeliaceae, de grande importância econômica entre as ornamentais, sendo muito cultivada em vaso e usada em decorações de interior e projetos paisagísticos.

A família Bromeliaceae Juss. possui cerca de 3.010 espécies, distribuídas em 56 gêneros. São de origem exclusiva do continente americano, havendo somente uma espécie (Pitcairnia feliciana) que habita a costa ocidental da África. Destaca-se como um dos principais componentes da flora e da fisionomia dos ecossistemas brasileiros, os quais abrigam aproximadamente $36 \%$ das espécies já catalogadas da família. Possui vários gêneros endêmicos, alguns deles (6) encontrados exclusivamente na Floresta Atlântica e seus ecossistemas associados (restingas, campos de altitude, manguezais, diversas matas), sendo considerado o bioma mais rico em plantas dessa familia (Stringheta et al., 2005; Moreira et al., 2006; SBBr, 2007). Em razão da grande procura pelas bromélias de valor ornamental, a retirada de seus ambientes naturais tem-se intensificado nos últimos anos, colocando algumas espécies em ameaça. Com a finalidade de conter tal exploração depredatória, muitos estudos têm sido realizados visando à produção de mudas em larga escala, proporcionando com isso mudas ao mercado, sem prejuízo para o ambiente. Como exemplos, podem ser citados os trabalhos realizados por Borges et al. (2001) e Rodrigues et al. (2004), que avaliaram a viabilidade de multiplicação in vitrode Ananas porteanus, uma espécie de abacaxi ornamental utilizada no paisagismo e na produção de flor de corte, e da bromélia-imperial Alcantarea imperialis, respectivamente.

A Unidade de Pesquisa e Conservação de Bromeliaceae (UPCB), Viçosa, MG, é um centro de estudos que tem como missão primordial promover a pesquisa científica em favor da conservação da família Bromeliaceae e dos ecossistemas onde vivem. Nessa unidade há uma coleção de bromélias vivas, um jardim temático e um setor de propagação. A coleção botânica é a base da pesquisa da UPCB, agrupando cerca de 1.000 espécies de todo o continente, com ênfase nas bromélias dos ecossistemas brasileiros. Esse acervo de plantas vivas possui hoje diversas espécies ameaçadas de extinção da flora do Brasil (Paula, 2004). Um problema constante na manutenção desse acervo é a infestação por plantas daninhas, sendo, entre outras, a brilhantina, Pilea microphylla, uma espécie já observada como problemática tanto na coleção quanto no setor de propagação.

Em estudo realizado para avaliar a seletividade e a eficácia de diversos herbicidas para controle de brilhantina no cultivo de bromélias, Freitas et al. (2004) verificaram que o herbicida oxyfluorfen foi eficiente no controle das plantas de brilhantina em aplicação dirigida, sem causar toxidez aparente às plantas de bromélia. A interferência das plantas daninhas, especialmente aquelas que se desenvolvem 
em ambientes sombreados e úmidos, a exemplo da brilhantina, e a eficiência do oxyfluorfen no controle destas também já foram demonstradas, no cultivo de mudas de estrelitzias (Strelitzia reginae) (Camargo et al., 2006).

As plantas daninhas são, indubitavelmente, um dos mais importantes fatores que afetam a economia agrícola em caráter permanente. Se, de um lado, a sua presença na cultura ocasiona prejuízos, o seu controle ainda acarreta despesas que oneram consideravelmente o custeio da cultura. Considerando que os estudos e trabalhos experimentais de manejo da flora daninha dependem da correta identificação botânica das espécies que a constituem na região em estudo, todo trabalho que visa melhor conhecimento das caracteristicas taxonômicas de tais plantas representa contribuição valiosa para a melhor solução do problema (Aranha et al., 1982).

São poucos os trabalhos sobre infestação de plantas daninhas em culturas ornamentais. Nesse contexto, um estudo foi realizado por Quigley (2003), em Ohio, a fim de buscar meios de reduzir a interferência negativa de tais plantas em coberturas ornamentais, e Franco et al. (2006) realizaram o levantamento fitossociológico do agrião-bravo, ocorrido em infestação natural no sistema de cultivo de crisântemo localizado em Artur Nogueira, próximo ao municipio de Holambra-SP.

Assim, objetivou-se neste trabalho definir as espécies de plantas daninhas criticas e potencialmente criticas no cultivo de bromélias, para que sejam realizados posteriormente estudos sobre o manejo mais adequado destas.

\section{MATERIAL E MÉTODOS}

No bromeliário da UPCB, foram realizadas visitas semanais no período de 16 de novembro de 2006 a 17 de janeiro de 2007, para caracterização do comportamento das espécies de plantas daninhas no cultivo de bromélias. A observação foi realizada utilizando-se um grupo de 680 vasos da coleção de bromélias vivas, que passaram pelo último controle manual em 10 de novembro de 2006.

A caracterização do comportamento das plantas daninhas consistiu em diagnosticar sua agressividade, observando-se fatores como tempo de aparecimento após o último controle, velocidade e intensidade de infestação, acompanhamento do primeiro ciclo reprodutivo, bem como seu mecanismo de dispersão de sementes.

Após o período de observação, foi feita a limpeza de todos os vasos e a triagem de todas as espécies daninhas, que foram identificadas e quantificadas. O sistema de classificação adotado foi o de Cronquist (1981), para as Angiospermae, e Tryon \& Tryon (1982), para as Pterydophyta. Para abreviação dos nomes dos autores, utilizou-se o proposto por Brummit \& Powell (1992).

Indivíduos férteis testemunhas das espécies críticas foram incluídos no Herbário VIC, do Departamento de Biologia Vegetal da UFV. Em seguida, foi feita a descrição morfológica, com comentários abordando aspectos vegetativos, reprodutivos e citações de sua ocorrência como invasoras em outras áreas. Ainda, foi realizada documentação fotográfica das espécies durante a infestação.

\section{RESULTADOS E DISCUSSÃO}

\section{Comportamento}

As plantas encontradas (Tabela 1) foram classificadas, de acordo com o seu grau de agressividade, em:

- Oportunistas- aquelas que foram observadas em no máximo seis vasos $(0,88 \%$ da amostra total).

- Potencialmente criticas- aquelas que foram observadas em até 15 vasos $(2,2 \%$ da amostra total), mas que, dependendo do tipo de manejo e época, poderiam vir a se tornar críticas.

- Críticas - aquelas que foram observadas em 29,4 e $44 \%$ da amostra total (680 vasos), ou 45,4 e $68,2 \%$ da porção de vasos infestados da amostra (440 vasos).

Na Figura 1 estão expostas algumas fotos da infestação por plantas daninhas nos vasos da coleção de bromélias vivas da UPCB, UFV.

Nas duas primeiras semanas após o último controle manual (10/11/2006), a brilhantina havia infestado 300 vasos (44\%) da coleção de bromélias vivas da UPCB e lançava seus primeiros pares de folhas. Já o agriãozinho 
Tabela 1 - Espécies de plantas daninhas críticas, potencialmente críticas e oportunistas identificadas nos vasos da coleção de bromélias vivas da UPCB, UFV

\begin{tabular}{|c|c|c|}
\hline Nome científico & Nome vulgar & Divisão/família \\
\hline \multicolumn{3}{|c|}{ Espécies críticas } \\
\hline Cardamine bonariensis Pers. & $\begin{array}{l}\text { Agriãozinho, agrião-amargo, agrião-bravo, } \\
\text { mostardinha, erva-holandesa }\end{array}$ & Magnoliophyta/ Brassicaceae \\
\hline Pilea microphylla (L.) Liebm. & $\begin{array}{l}\text { Brilhantina, beldroega, folha-gorda, planta- } \\
\text { artilheira }\end{array}$ & Magnoliophyta/ Urticaceae \\
\hline \multicolumn{3}{|c|}{ Espécies potencialmente críticas } \\
\hline Crepis japonica (L.) Benth. & Barba-de-falcão & Magnoliophyta/ Compositae \\
\hline Cyperus difformis $\mathrm{L}$. & Tiririca-do-brejo & Magnoliophyta/ Cyperaceae \\
\hline Cyperus rotundus $\mathrm{L}$. & Tiririca & Magnoliophyta/ Cyperaceae \\
\hline Brachiaria decumbens Stapf. & Capim-braquiária & Magnoliophyta/ Gramineae \\
\hline Eleusine indica (L.) Gaertn. & Capim-pé-de-galinha & Magnoliophyta/ Gramineae \\
\hline Oxalis corniculata L. & Azedinha & Magnoliophyta/ Oxalidaceae \\
\hline Pteridium aquilinum(L.) Kuhn & Samambaia-das-taperas & Pteridophyta/ Pteridaceae \\
\hline \multicolumn{3}{|c|}{ Espécies oportunistas } \\
\hline Amaranthus retroflexus L. & Caruru-gigante & Magnoliophyta/Amaranthaceae \\
\hline Ageratum conyzoides $\mathrm{L}$. & Mentrasto & Magnoliophyta/Compositae \\
\hline Conyza bonariensis (L.) Cronquist & Buva & Magnoliophyta/ Compositae \\
\hline Emilia sonchifolia (L.) DC & Falsa-serralha & Magnoliophyta/Compositae \\
\hline Galinsoga parviflora Cav. & Botão-de-ouro & Magnoliophyta/ Compositae \\
\hline Gnaphalium spicatum Mill. & Macela & Magnoliophyta/ Compositae \\
\hline Sonchus oleraceus L. & Serralha & Magnoliophyta/ Compositae \\
\hline Taraxacum officinale F.H. Wigg. & Dente-de-leão & Magnoliophyta/ Compositae \\
\hline Phyllanthus tenellus Roxb. & Quebra-pedra & Magnoliophyta/Euphorbiaceae \\
\hline Panicum maximum Jacq. & Capim-colonião & Magnoliophyta/ Gramineae \\
\hline Oxalis latifolia Kunth. & Trevo-azedo & Magnoliophyta/ Oxalidaceae \\
\hline Solanum americanum Mill. & Maria-pretinha & Magnoliophyta/ Solanaceae \\
\hline
\end{tabular}

alcançou a máxima infestação três a quatro semanas após o último controle, infestando 200 vasos $(29,4 \%)$ da coleção. Contudo, quanto ao primeiro ciclo reprodutivo, as espécies de agriãozinho atingiram o estádio reprodutivo, em média, em duas semanas e lançaram sementes na quarta semana após o lançamento dos primeiros pares de folhas, enquanto as espécies de brilhantina alcançaram o estádio reprodutivo em cerca de quatro semanas e lançaram sementes seis semanas depois de sua emergência .

Entre as espécies de plantas daninhas consideradas potencialmente críticas, o estádio reprodutivo foi atingido dois meses (oito semanas) após a emergência destas e não foi observado mecanismo eficiente de dispersão de sementes entre os vasos, uma vez que, por se tratar de um ambiente protegido, o vento não exercia ação considerável na anemocoria.
Os vasos que apresentavam cobertura ou "tapete" - formada por briófitas (10 ou 1,5\%), britas ornamentais (10 ou 1,5\%) e casca de eucalipto picado (220 ou $32,3 \%)$ - mostraram pouca ou nenhuma invasão por plantas daninhas. Provavelmente, a germinação destas pode ter sido prejudicada por mudanças das condições fisiológicas (luz, amplitude térmica, entre outros) necessárias para ocorrência do fenômeno ou por efeitos alelopáticos (Silva et al., 2006); portanto, novos estudos envolvendo tais fatores isoladamente devem ser realizados.

Geralmente, as plantas daninhas que se desenvolvem em uma cultura são aquelas que apresentam necessidades fisiológicas quanto aos recursos e condições semelhantes às da cultura infestada (Silva et al., 2006). Portanto, o sombreamento, a adubação e a grande quantidade de água no substrato, necessários ao 


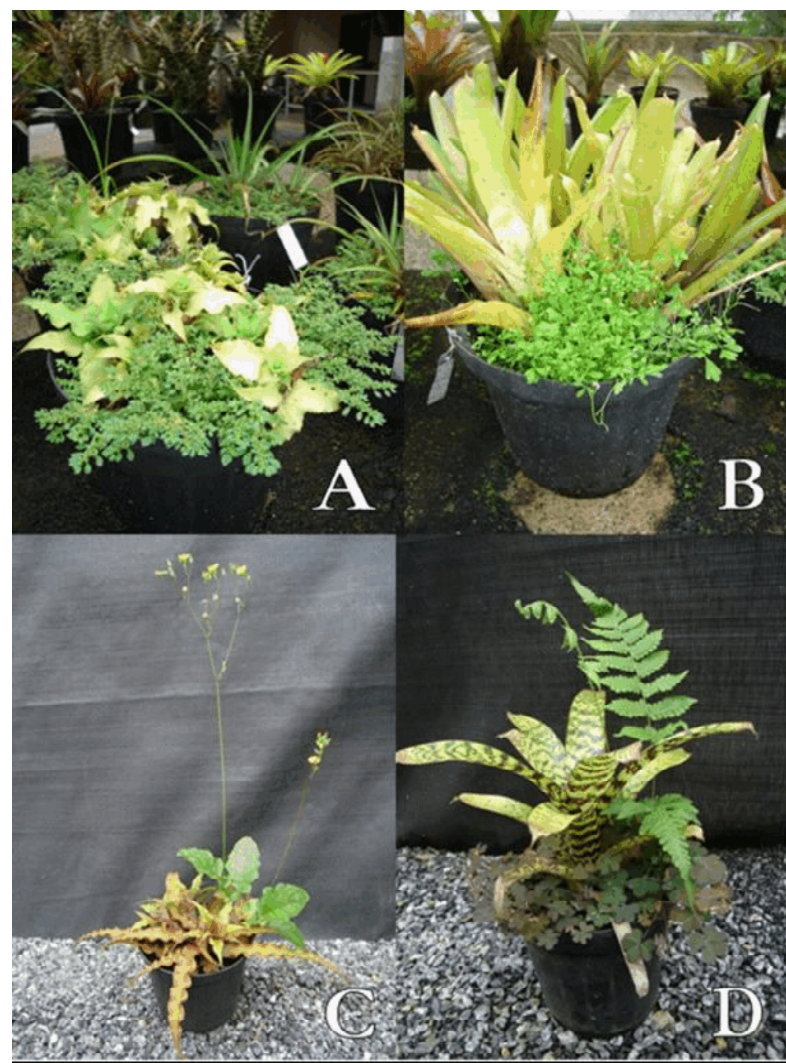

Figura 1 - Vasos da coleção de bromélias vivas da UPCB, UFV, infestados com as plantas daninhas: A) brilhantina; B) agriãozinho; C) barba-de-falcão; D) samambaia-dastaperas e azedinha.

cultivo de bromélias em ambientes protegidos, propiciaram a germinação e o desenvolvimento de espécies daninhas muito competitivas, como a brilhantina (Pilea microphylla) e o agriãozinho (Cardamine bonariensis). A partir da caracterização da habilidade competitiva de espécies ornamentais usadas em cobertura de solo, como preferência por sol ou sombra, Quigley (2003), em Ohio, utilizou-se dos conhecimentos adquiridos, conjugando-os com o sombreamento por copas de árvores para reduzir a interferência causada por plantas daninhas.

\section{Triagem}

Os vasos que possuiam brilhantina tinham seis indivíduos em média (Tabela 2), variando de 4 a 17 em alguns vasos. Os vasos que foram infestados com agriãozinho possuíam em média 13 indivíduos cada (Tabela 2), esse número variou de 7 a 43 indivíduos em alguns vasos.

\section{Descrições de espécies críticas}

\section{Cardamine bonariensis}

Herbácea anual rizomatosa, muito ramificada, caules decumbente-eretos, $9-14 \mathrm{~cm}$ compr., raízes adventícias nos nós. Folhas simples, alternas, glabras; basais 2,2-3,2 cm compr., em forma de leque com bordos crenados, longo pecioladas; apicais 3,14,7 cm compr., pin atipartidas, pecioladas. Inflorescência racimosa; flores actinomorfas, pequenas, diclamídeas, tetrâmeras; corola alva, sépalas 1,5-2 mm compr.; androceu tetradinamo; ovário súpero, bicarpelar, estilete ínfimo $1 \mathrm{~mm}$ compr., estigma capitado. Fruto síliqua muito mais longo do que largo, glabro; sementes 2030 , comprimidas, com bordos emarginados, dispostas em uma fileira.

Nativa da Europa e disseminada nas regiões Sul e Sudeste do Brasil, propaga-se por sementes (Lorenzi, 2000). É considerada uma planta daninha medianamente freqüente, infestando principalmente jardins, viveiros de mudas e hortas caseiras, e apresenta ciclo curto, preferindo locais úmidos e sombreados (Lorenzi, 2000). A espécie produz grande quantidade de sementes pequenas, que são dispersas por metros de distância, no momento da deiscência explosiva do fruto tipo síliqua. Esta espécie é referida como enraizada emergente em canais de irrigação na província de Huaylas, Áncash, no Peru (Monsalve \& Cano, 2003). Também foi encontrada infestando canteiros de mudas de flores sob cultivo protegido, no interior das estufas e nas bandejas de mudas em uma propriedade produtora de mudas de crisântemo, localizada em Artur Nogueira, SP. A infestação na área amostrada foi de cerca de 350 plantas de agriãozinho por metro quadrado, de tal forma que a planta daninha em estádio adulto recobre toda a superficie entre as plantas de crisântemo (Franco et al., 2006). $\mathrm{O}$ mesmo autor afirma que devido à grande produção de sementes por planta e ao seu pequeno tamanho, associado ao curto periodo do seu ciclo biológico, o controle do agriãozinho requer gastos com mão-de-obra manual para a sua eliminação e que a sua dispersão para outras localidades de cultivo de crisântemo e flores ornamentais torna-se preocupante para outros municípios produtores. 
Material examinado: BRASIL. Minas Gerais: Viçosa, UFV, UPCB, XII/2006 (fl., fr.), Rodrigues $66 \&$ Reis (VIC).

\section{Pilea microphylla}

Herbácea perene, hábito de crescimento cespitoso ou prostrado, muito ramificada, 9$18 \mathrm{~cm}$ compr., caule suculento, algumas vezes ligeiramente lenhoso na base. Ramagem densa; folhas simples, opostas, diminutas e carnosas, obovadas, elipticas, oblanceoladas, ou oblongas, 2-5 x 1-2 mm, apresentando 1 nervura central, face adaxial com cistólitos elípticos, face abaxial finamente reticulada, bordos inteiros, subsésseis; estipulas $1 \mathrm{~mm}$ compr. Inflorescências em glomérulos sésseis ou cimas; flores uniss exuadas, monoclamídeas; flores masculinas simétricas, tetrâmeras, com filetes dobrados no botão floral, estames 4, anteras globosas, rimosas, com deiscência explosiva; flores femininas com cálice assimétrico, 3-lobado, de segmentos concrescidos, ovário súpero, subséssil, estigma penicelado, 1 óvulo. Frutos aquênios elipsóides 0,5-1 mm compr.

Originária da América Tropical, propagase por sementes (Lorenzi, 2000), diminutas como pó, facilmente dispersas por manuseio. É uma planta amplamente cultivada para fins ornamentais; contudo, torna-se indesejável quando cresce espontaneamente em fendas de calçadas e paralelepipedos, hortas caseiras, pomares e em ambientes protegidos. Pouco exigente em condições de solo, mas requer bom suprimento de umidade e condições de luz difusa (Lorenzi, 2000). Estudos sistemáticos conduzidos em casas de vegetação do Jardim Botânico de Varsóvia, Polônia, de 1992 a 1995, revelaram que a flora de espécies daninhas é muito rica, apresentando um total de 243 táxons de plantas vasculares catalogadas. $P$. microphylla, entre as plantas estudadas, mereceu atenção especial, pois foi uma das espécies trazidas acidentalmente para as casas de vegetação, juntamente com outro material vegetal, passando a constituir um grupo numeroso e freqüente na área em estudo (Galera \& Ratyska, 1999). Em trabalho realizado para avaliar o controle químico da brilhantina em vasos de bromélia e estrelítzia, o herbicida oxyfluorfen promoveu excelente controle desta espécie daninha, por meio da pulverização em área dirigida, sem causar danos às plantas da cultura (Freitas et al., 2004; Camargo et al., 2006).

Material examinado: BRASIL. Minas Gerais: Viçosa, UFV, UPCB, XII/2006 (fl., fr.), Rodrigues $65 \&$ Reis (VIC).

A espécie daninha Crepis japonica não foi descrita neste trabalho por não ter alcançado número de indivíduos considerado crítico, porém merece atenção especial, por se tratar de uma planta potencialmente crítica. Segundo Lorenzi (2000), é uma planta daninha pouco freqüente, ocorrendo principalmente em viveiros de mudas, onde é considerada uma séria infestante; também é encontrada em hortas e jardins e parece ter sido introduzida recentemente com mudas de plantas ornamentais, estando no momento em franca disseminação. É uma espécie muito freqüente nos ambientes mais úmidos e sombreados do campus da UFV. Apresenta exigência de solos férteis e úmidos, com ambientes de meia-sombra. Suas sementes são dispersas pelo vento e, talvez por esse motivo, ela não é muito disseminada entre os vasos da coleção da UPCB, visto que, por se tratar de ambiente protegido com ventos fracos, a anemocoria é prejudicada.

Como exposto pelos resultados, as espécies de plantas daninhas críticas no cultivo de Bromeliaceae são brilhantina e agriãozinho. Deve-se atentar para que outras espécies

Tabela 2 - Dados de triagem de plantas daninhas na UPCB, UFV

\begin{tabular}{|l|c|c|c|}
\hline \multicolumn{1}{|c|}{ Espécie } & $\begin{array}{c}\text { Número de vasos } \\
\text { observados }\end{array}$ & $\begin{array}{c}\text { Número total de } \\
\text { indivíduos }\end{array}$ & $\begin{array}{c}\text { Número médio de } \\
\text { indivíduos por vaso }\end{array}$ \\
\hline Cardamine bonariensis & 200 & 2.570 & 12,85 \\
\hline Pilea microphylla & 300 & 1.856 & 6,18 \\
\hline $\begin{array}{l}\text { Espécies oportunistas + espécies } \\
\text { potencialmente críticas }\end{array}$ & 40 & 64 & 1,6 \\
\hline
\end{tabular}


potencialmente criticas características de ambientes férteis, úmidos e sombreados, como a barba-de-falcão, não venham a se tornar criticas.

\section{LITERATURA CITADA}

ARANHA, C.; BACCHI, O.; LEITÃO FILHO, H. F. Plantas invasoras de culturas, Campinas: Instituto Campineiro de Ensino Agrícola, 1982. v. 1. 291 p.

BORGES, N. S. S.; CORREIA, D.; LIMA, R. N. Multiplicação e enraizamento in vitro de brotos de abacaxi ornamental Ananas porteanus Hort Veitch ex C. Koch. Ceará: Embrapa Agroindústria Tropical, 2001. 5 p.

BRUMMIT, R. K.; POWELL, C. E. Authors of plant names. Kew: The Royal Botanic Gardens, 1992. 732 p.

CAMARGO, J. R. et al. Eficácia do oxyfluorfen no controle da Pilea microphylla no cultivo de mudas de estrelítzias. In: SIMPÓSIO DE INICIAÇÃO CIENTÍFICA DA UFV, 15., 2006, Viçosa , MG. Resumos... Viçosa , MG: 2006. v. 1. p. 256.

CRONQUIST, A. An integrated system of classification of flowering plants. New York: Columbia University Press, 1981. $1262 \mathrm{p}$.

FRANCO, D. A.S. et al. Levantamento fitossociológico do agrião amargo (Cardamine bonarien sis Pers.) em sistema de produção de crisântemo. Campinas: Centro

Experimental Central do Instituto Biológico, 2006. 2 p.

FREITAS, F. C. L. et al. Controle químico de plantas daninhas em bromeliários. In: CONGRESSO BRASILEIRO DA CIÊNCIA DAS PLANTAS DANINHAS, 24., 2004, São Pedro. Anais... São Paulo: 2004.

GALERA, H.; RATYSKA, H. Greenhouse weeds in the botanical garden of Pas in Warsaw-Powsin. Acta Soc. Bot.Poloniae, v. 68, n. 3, p. 227-236, 1999.
LORENZI, H. Plantas daninhas do Brasil: terrestres, aquáticas, parasitas, tóxicas e medicinais. 3. ed. Nova Odessa: Plantarum, 2000. 608 p.

MONSALVE, C.; CANO, A. La familia Brassicaceae en la provincia de Huaylas, Áncash. R. Peruana Biol., v. 10, n. 1, p. 20-32, 2003.

MOREIRA, B. A.; WANDERLEY, M. G. L.; BARROS, M. A.V.C. Bromélias: importância ecológica e diversidade. Taxonomia e morfologia - Curso de Capacitação de Monitores. São Paulo: Instituto de Botânica, 2006. 12 p.

PAULA, C. C. Unidade de pesquisa e conservação de Bromeliaceae. Vidalia, v. 2, n. 1, 2004. (Edição especial)

QUIGLEY, M. F. Reducing weeds in ornamental groundcovers under shade trees through mixed species competition. Hort. Technol., v. 13, n. 1, p. 85-89, 2003.

RODRIGUES, T. M. et al. Desenvolvimento de mudas de bromélia imperial (Alcantarea imperialis) em diferentes substratos. Ci. Agrotec., v. 28, n. 4, p. 757-763, 2004.

SOCIEDADE BRASILEIRA DE BROMÉLIAS - SBBr Disponível em: <www.bromelia.org.br/> Acesso em: 10/02/ 2007.

SEBRAE Cadeia produtiva da floricultura na Grande São Luís. São Luís: 2003. 61 p.

SILVA, A. A. et al. Biologia de plantas daninhas. In: SILVA, A. A.; SILVA, J. F. Tópicos em manejo de plantas daninhas. Viçosa, MG: Universidade Federal de Viçosa, 2006. $318 \mathrm{p}$.

STRINGHETA, A. C. O. et al. Germinação de sementes e sobrevivência das plântulas de Tillandsia geminiflora Brongn, em diferentes substratos. Acta Sci. Agron., v. 27, n. 1, p. 165-170, 2005.

TRYON, R. M.; TRYON, A. F. Ferns and allied plants, with special reference to tropical America. New York: Springer-Verlag, 1982. 857 p. 